\title{
Geografías e historias de aprendizaje de docentes de secundaria. Intersecciones, tránsitos y zonas de no saber
}

\section{Secondary School Teachers' Learning Geographies and Histories. Intersections, Transits and Areas of Not Knowing}

\author{
Alejandra Bosco*1 \\ Alejandra.bosco@uab.cat \\ Cristina Alonso Cano** \\ Cristina.alonso@ub.edu \\ Raquel Miño Puigcercós** \\ rmino@ub.edu \\ * Universitat Autònoma de Barcelona, España \\ **Universitat de Barcelona, España
}

\section{Resumen:}

El artículo muestra parte de los procesos y resultados de un proyecto de investigación que explora qué, cómo, con qué y dónde aprenden los docentes de secundaria dentro y fuera de sus centros. Tras presentar la perspectiva onto-epistemológica en la que se sitúa el estudio y los avances que se propone alcanzar, nos referirnos brevemente a la aproximación metodológica y a los participantes en la investigación. A continuación, nos centramos en ocho docentes que trabajan en uno de los tres institutos que han colaborado en el estudio. Para ello, situamos el contexto y los procesos llevados a cabo y realizamos una aproximación a sus geografías e historias de aprendizaje. A continuación, se pro-

\begin{abstract}
:
This article shows part of the processes and results of a research project that explores what, how, with what and where secondary school teachers learn inside and outside their schools. After locating the onto-epistemological perspective in which the study is situated and the advances to be achieved, we briefly refer to the methodological approach and to the participants in the piece of research. Next, we focus on eight teachers who work in one of the three secondary school that have collaborated in the study. To do this, we situate the context and the processes involved in the configuration of the teachers' learning geographies and histories. To this end, the process of analysis employed
\end{abstract}

1 Dirección para correspondencia (correspondence address):

Alejandra Bosco. Universitat Autònoma de Barcelona. Departamento de Pedagogía Aplicada. Plaça del Coneixement s/n Edifici G6, $2^{\circ}$ planta. Campus UAB. Cerdanyola del Vallès, 08193 Barcelona (España). 
Geografías e historias de aprendizaje de docentes de secundaria. Intersecciones, tránsitos y zonas de no saber

Alejandra Bosco, Cristina Alonso Cano y Raquel Miño Puigcercós

blematiza el proceso de análisis seguido y se identifican los escenarios en los que aprenden los docentes, los tránsitos entre escenarios y las nociones de aprendizaje que emergen en sus geografías e historias de aprendizaje. Finalmente, se sitúan las aportaciones que estas prácticas de investigación narrativa pueden representar para la propia investigación educativa y la formación docente.

\section{Palabras clave:}

Cartografías de aprendizaje; investigación narrativa; métodos visuales; pensamiento docente. is problematized and the scenarios in which teachers learn are identified, as are the transitions between scenarios and the notions of learning that emerge in their learning geographies and histories. Finally, we refer to the contributions that these practices of narrative research can make to educational research and the professional development of teachers.

\section{Key Words:}

Learning cartography; narrative research; teachers' thinking; visual methods.

\section{Résumé:}

L'article présente une partie des processus et des résultats d'un projet de recherche qui explore les types d'apprentissages, mais aussi comment, avec quoi et où les enseignants du secondaire apprennent dans leurs centres et à l'extérieur de ceux-ci. Après avoir présenté la perspective onto épistémologique dans laquelle se situe l'étude et les progrès qu'elle prétend apporter, nous nous référons brièvement à l'approche méthodologique et aux participants de la recherche. Ensuite, nous nous concentrons sur huit enseignants qui travaillent dans l'un des trois lycées ayant collaboré à l'étude. Pour cela, nous situons le contexte et les processus développés, pour réaliser une approximation de leurs géographies et histoires d'apprentissage. Le processus d'analyse suivi est ensuite problématisé et s'identifient les scénarios avec lesquels les enseignants apprennent identifiés, ainsi que les transits entre scénarios et les notions d'apprentissage qui émergent dans leurs géographies et leurs histoires d'apprentissage. Finalement, nous situons les contributions de ces pratiques de recherche narrative pour la recherche en éducation et la formation des enseignants.

\section{Mots-clés:}

Cartographie d'apprentissage; recherche narrative; méthodes visuelles; pensée enseignante.

Fecha de recepción: 22-11-2018

Fecha de aceptación: 30-5-2019 


\section{Introducción y marco teórico}

En las últimas décadas del siglo XX surgió un creciente interés por el papel fundamental del profesorado en los procesos de enseñanza y aprendizaje. Publicaciones como las de Sarason (1990), Stenhouse (1975) o Bruner (1977) comenzaron a cuestionar la figura del docente como "caja negra", al desvelar las perniciosas consecuencias de pensar en el profesorado como un "mero ejecutor" de las ideas y decisiones de otros. Por otro lado, el considerable desarrollo de la investigación en torno al cambio y la mejora de la educación, ha ido reconociendo a los docentes como figuras clave -sin desconsiderar las condiciones en las que se ven obligados a llevar a cabo su trabajo-, para favorecer o dificultar iniciativas de mejora de la práctica educativa (Fullan, 2016; Hargreaves, 1994; Stoll y Fink, 1996).

En este contexto, han proliferado el interés y las investigaciones tanto sobre el aprendizaje y el saber profesional de los docentes (Escudero, Cutanda y Trillo, 2017; James y McCormicki, 2009; Korthagen, 2017; Mishra y Koehler, 2006; Putnam y Borko, 2000; Shulman, 1987; Shulman y Shulman, 2004; Vélaz de Medrano y Vaillant, 2009), como sobre el pensamiento, las teorías implícitas y el saber tácito del profesorado (Calderhead, 1987; McNamara, 2006; Rodrigo, Rodríguez y Marrero, 1993; Tenti, 2010). Una característica común a prácticamente todas las considerables aportaciones a estos campos, es que se centran en y están delimitadas por los contextos institucionales, desconsiderando a menudo que, como argumenta Tenti (2010):

toda práctica científica está atravesada por elementos personales tales como pasiones, ideales, esperanzas, visiones, etc., no nos es neutral como algunos pretenden. [...] El conocimiento tácito ocupa un lugar central en el trabajo científico, pero es aún más importante en profesiones prácticas como la medicina o la docencia (p. 14-15).

Y, lo que es más, la cuestión de cómo, con quién y dónde se generan esas 'pasiones, ideales, esperanzas, visiones'. Investigaciones realizadas desde perspectivas narrativas y etnográficas (Ball y Goodson, 1985; Carr y Lee, 2012; Goodson y Hargreaves, 1996; Goodson y Sikes, 2001; Sancho, 2011, 2013; Sancho y Hernández, 2014) evidencian la imposibilidad de reducir el aprendizaje y el pensamiento del profesorado al 
Geografías e historias de aprendizaje de docentes de secundaria. Intersecciones, tránsitos y zonas de no saber

Alejandra Bosco, Cristina Alonso Cano y Raquel Miño Puigcercós

estrecho marco institucional. Porque lo personal, profesional, cultural y social están profundamente interconectados y el docente, como el resto de las personas, aprende en interacción con lo que le rodea a lo largo y lo ancho de la vida (Banks et al., 2007).

Es en esta línea de pensamiento en la que nos planteamos el proyecto de investigación "APREN-DO - Cómo aprenden los docentes de secundaria: Implicaciones educativas y retos para afrontar el cambio social" ${ }^{2}$. Una investigación en la que hemos explorado, con un grupo de profesores y profesoras de esta etapa escolar, qué, cómo, con qué y dónde aprenden dentro y fuera de sus centros. La pregunta clave que ha guiado nuestra indagación ha sido: ¿Qué nos permite pensar, qué conceptos nos permite hacer emerger, el proceso de creación de cartografías por parte de los docentes sobre sus tránsitos de aprendizaje dentro y fuera de las instituciones educativas?

Para abordar esta cuestión, hemos partido de una concepción del aprendizaje como movimiento o proceso de devenir, y del aprendiz -en este caso, del docente- como sujeto que se encuentra constantemente descifrando y generando conexiones significativas con el mundo que le rodea (Fendler, 2013). Basándonos en el lenguaje de Deleuze y Guattari y tomando en cuenta el trabajo desarrollado por Fendler (2013) destacamos que concebir al aprendiz como sujeto nomádico no implica solamente tomar en cuenta sus movimientos físicos entre contextos, sino más bien comprender sus experiencias de aprendizaje como cambio constante al entrar en territorios desconocidos y al experimentar procesos de descubrimiento.

En este sentido, las cartografías visuales elaboradas por el profesorado han sido a la vez una herramienta para visibilizar sus movimientos y cambios experimentados como aprendices y un punto de partida para indagar en el carácter nomádico de su aprendizaje. El uso de metáforas visuales por parte de los docentes fue lo que les llevó a relatar sus historias de aprendizaje, entendidas como relatos autobiográficos que abordan las relaciones sociales, los espacios, los momentos, las herramientas, las prácticas y los eventos que han sido significativos en sus "trayectorias de aprendizaje" (Erstad, 2015; Miño Puigcercós, 2018).

De aquí que destaquemos el potencial de dialogar acerca de las geo-

2 Se trata de un proyecto coordinado y los colegas del grupo [nombre del grupo] de la Universidad del País Vasco, se centran en el profesorado de educación infantil y primaria. 
grafías de aprendizaje de los docentes como forma de análisis de los tránsitos, las continuidades y las discontinuidades en las trayectorias que se producen entre las situaciones de aprendizaje que vive el profesorado a lo largo de sus vidas. Esta aproximación ontoepistémica y metodológica nos ha permitido profundizar en las historias personales de ocho docentes que trabajan en uno de los tres institutos que han colaborado en el estudio, así como identificar algunos espacios y procesos a través de los cuales han aprendido, no solamente espacios estriados -formales y jerárquicos-, sino también llanos -informales, desestructurados y caóticos- (Deleuze y Guattari, 1980/2004).

A continuación, situamos el contexto y los procesos llevados a cabo y realizamos una aproximación a las geografías e historias de aprendizaje de los docentes. Para ello, se problematiza el proceso de análisis seguido y se identifican los escenarios en los que aprenden los docentes, los tránsitos entre escenarios y las nociones de aprendizaje que emergen en sus relatos. Finalmente, se sitúan las aportaciones que estas prácticas de investigación narrativa pueden tener para la construcción de la identidad docente, desde las voces de los participantes.

\section{Aproximación metodológica}

La perspectiva metodológica se encuadra en un nuevo giro que se ha ido instalando en la agenda de la investigación social que, aunque con menos fuerza que en otros ámbitos, también se está desarrollando en la indagación educativa. Nos referimos al giro espacial que, procedente de la Geografía, implica una reelaboración de la noción y significado de la espacialidad en prácticamente todas las disciplinas (Warf y Arias, 2008). En este contexto, Ilegamos a las cartografías visuales como dispositivos epistemológicos y metodológicos de investigación, que forman parte de una cierta tradición en las Ciencias Sociales y en la Educación (Ruitenberg, 2007; Ulmer y Koro-Ljungberg, 2015).

En nuestra investigación, tomamos en particular la noción de "cartografías esquizoanalíticas" de Guattari (2012), quien las considera como configuraciones relacionales que cambian el estado y el estatus en función de ensamblajes particulares. También como "método inventivo" (Lury y Wakeford, 2012), como un "aparato de captura" que territorializa lo nuevo y lo singular, pudiendo mostrar conjuntos interrelacionados. 
Geografías e historias de aprendizaje de docentes de secundaria. Intersecciones, tránsitos y zonas de no saber

Alejandra Bosco, Cristina Alonso Cano y Raquel Miño Puigcercós

Una manera de captura que ayuda a dar sentido al aprendizaje a través de mostrar diferentes contextos y tiempos, así como su relación. La cartografía, se convierte en metafórica en su aplicación porque muestra conexiones, trazados, caminos, redes y hasta trayectorias de aprendizaje no necesariamente conectadas espacialmente hablando. La cartografía no sólo se ve adecuada porque puede mostrar fácilmente el carácter espacial y temporal del aprendizaje, sino también porque cuestiona las interconexiones más fácilmente que el discurso narrativo convencional (Sefton-Green, 2017).

Esta noción resulta relevante para nuestro propósito de investigación, ya que puede tomarse como una estrategia para generar "conocimiento" y relacionarse con la teoría, al permitirnos combinar diferentes elementos, mantener un hilo conductor y articulador de las narrativas de los docentes de secundaria. En nuestro caso, las cartografías no son un resultado, o una imagen desencadenante, sino un espacio de pensamiento y de conexión entre las experiencias de aprendizaje nómadas de los docentes y sus representaciones visuales. La noción de aprendizaje nómada (Fendler, 2015) se utiliza para dar cuenta de aquellas interacciones que subvierten el proceso de aprendizaje tal y como suele ser considerado desde la Psicología y la Pedagogía (Atkinson, 2011), revelando lo que constituye sus límites, los flujos y las intensidades. Esto implica concebir al aprendiz como "sujeto que navega siguiendo caminos relacionados con sus propios intereses, a través de rutas que probablemente se cruzan y se desvían del currículum escolar formal" (Fendler, 2013, p. 787).

Esta noción nos invita a considerar cómo acceder a estos "lugares" más allá de los marcos preestablecidos en la enseñanza y la investigación dominantes en las maneras de acercarse a la investigación biográfica en general y a la de historias de vida en particular. Algunos autores como Braidotti $(2006,2014)$ y Jackson y Mazzei (2012) nos han guiado a la hora de explorar y significar lo que está fuera del marco de las cartografías de aprendizaje que los docentes de secundaria han realizado en los dos encuentros a los que les hemos invitado a participar.

\section{Contexto, participantes y proceso de investigación}

En el desarrollo de este estudio han participado un total de 29 docentes de secundaria, 26 de los cuales trabajan en 3 institutos (Tabla 1). 
Tabla 1

Participantes y producciones realizadas.

\begin{tabular}{|l|l|l|l|}
\hline \multicolumn{1}{|c|}{ Centros } & \multicolumn{1}{c|}{ Número de docentes } & \multicolumn{1}{c|}{ Cartografías } & \multicolumn{1}{c|}{ Videos } \\
\hline 1 & 11 & 10 & $10+1$ \\
\hline 2 & 8 & 8 & $8+1$ \\
\hline 3 & 7 & 7 & $7+1$ \\
\hline Mixto & 3 & 3 & 3 \\
\hline TOTAL & 29 & 28 & $28+3$ \\
\hline
\end{tabular}

Fuente: elaboración propia.

De los 29 docentes que han participado en la investigación, para este trabajo nos hemos centrado en ocho profesoras y profesores que trabajan en uno de los tres institutos que ha colaborado en el estudio. El trabajo realizado con este grupo de docentes se llevó a cabo en su instituto, un centro público de Educación Secundaria Obligatoria (ESO), Bachillerato y Formación Profesional (Grado medio y superior) ubicado en una ciudad colindante con Barcelona.

La investigación empezó con la invitación, por parte del equipo de investigación, a una de las docentes del centro a participar en el proyecto. Esta profesora propuso al claustro la posibilidad de participar como grupo y organizó un encuentro entre los investigadores implicados y un grupo de docentes interesados. Este encuentro con 6 profesoras y 2 profesores, con una media de 10 años de experiencia docente, tuvo lugar en la biblioteca del centro. Empezamos con una breve introducción del proyecto, la presentación de todos los asistentes y la propuesta de configurar cartografías de aprendizaje.

Los participantes habían recibido con antelación una descripción del proyecto y unas preguntas de contextualización que les invitaban a pensar y a reflexionar sobre cómo plasmarían en una cartografía sus recorridos, trayectorias y experiencias de aprendizaje. También se les hizo llegar un documento de consentimiento informado sobre su participación voluntaria en la investigación y la cesión de los derechos de imagen e información. 
Geografías e historias de aprendizaje de docentes de secundaria. Intersecciones, tránsitos y zonas de no saber

Alejandra Bosco, Cristina Alonso Cano y Raquel Miño Puigcercós

Algunas participantes llegaron a la sesión con imágenes, recortes de revistas o esquemas sobre la cartografía que pensaban realizar, mientras que el resto empezó la cartografía en el mismo lugar. Cada uno construyó su cartografía individualmente acompañado por un miembro del equipo investigador. La función de los investigadores tenía que ver con ayudarles a formular sus propias preguntas en torno al aprendizaje, recuperar experiencias, personas, lugares y materiales a través de los que habían aprendido a ser docentes. Todos partieron de una o varias metáforas que les permitieron pensar acerca de lo que significaba para ellos aprender o sobre el tipo de procesos, conexiones y trayectorias a través de los que consideraban que aprendían.

La sesión fue documentada visualmente y finalizó con la grabación audiovisual de los relatos de los participantes frente a su cartografía. En esta grabación se les invitó a narrar el proceso que habían seguido para crear sus cartografías, aquello que habían plasmado a través de metáforas visuales y lo que les había representado participar en este estudio.

Con posterioridad al encuentro, realizamos un análisis narrativo y dialógico de las cartografías. Para ello, en primer lugar, recuperamos toda la documentación textual, visual y audiovisual que habíamos producido durante la sesión sobre cada participante. A continuación, creamos un documento para cada docente que recogía: su fotografía, la presentación que hizo sobre sí mismo, fotografías del proceso de producción, una fotografía de la cartografía, la transcripción de su relato y las notas de campo del investigador que acompañó el proceso. En la última columna, 'Lo que nos permitió pensar', escribimos las resonancias que como investigadoras habíamos experimentado frente a cada cartografía. Intentamos evitar la mirada evaluadora que en ocasiones subyace a los relatos en la investigación educativa. Se trataba de indagar cómo estos docentes explicaban qué y cómo aprendían. En ocasiones nos sugerían formas particulares de aprender que podíamos asociar a diferentes tradiciones pedagógicas o concepciones psicológicas del aprendizaje, aunque no siempre fue así. No se trataba de interpretar desde la teoría, sino de indagar y dialogar con la intención de descolonizar el aprendizaje como teoría y explorarlo encarnado en diferentes experiencias.

En la segunda reunión, les mostramos un vídeo editado por dos miembros del equipo destacando dos aspectos centrales en las historias 
de aprendizaje de los docentes: la relación entre el dentro y el fuera del centro y sus concepciones sobre aprendizaje. También compartimos nuestras resonancias con cada uno de los participantes, lo que nos llevó a continuar reflexionando sobre y a partir de sus cartografías. El diálogo establecido, si bien fue fructífero, no en todos los casos alcanzó las cotas esperadas. El intercambio, por su parte, fue tímido, como si no se hubieran dado permiso para una construcción dialógica en la que no sólo tienen cabida las ideas sino también la carga emocional que implica reflexionar sobre cómo cada uno aprende (Cumming, 2015).

\section{Geografías e historias de aprendizaje}

Este apartado contiene una aproximación narrativa a las ocho geografías (imagen 1, 2, 3, 4, 5, 6, 7 y 8) e historias de aprendizaje, entendidas como un diálogo entre los docentes participantes y las investigadoras. Nos hemos centrado en los escenarios en los que aprenden los docentes, los tránsitos entre escenarios y las nociones de aprendizaje que emergen en sus historias.

\subsection{La pasión por la palabra y la reflexión}

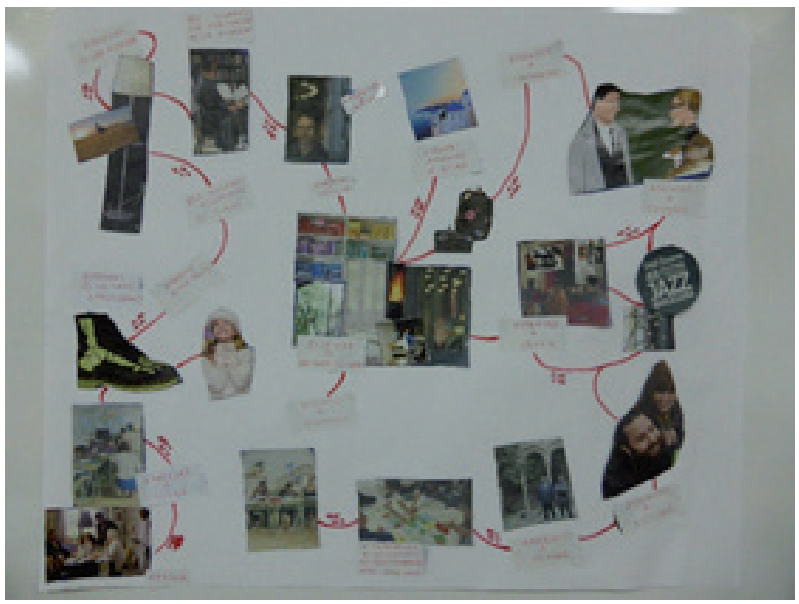

Imagen 1. Cartografía de Mónica. Fotografía independiente.

Fuente: autoría propia. 
Geografías e historias de aprendizaje de docentes de secundaria. Intersecciones, tránsitos y zonas de no saber

Alejandra Bosco, Cristina Alonso Cano y Raquel Miño Puigcercós

Mónica es profesora de castellano. En su presentación se define como una mujer a la que le apasiona la palabra y le gusta reflexionar sobre lo que hace. Una docente que intenta transmitir a sus alumnos su pasión por la lectura y la escritura.

En la cartografía de Mónica no hay improvisación. Durante el fin de semana estuvo reflexionando, pensando... y llegó a la sesión con toda una serie de cartulinas y fotografías recortadas para crear su cartografía. La Cartografía de Mónica desprende pasión, reflexión, luz (más que sombra) e ilusión. Está conformada por un conjunto de imágenes (y de relaciones entre ellas) que representan las experiencias y vivencias cuidadosamente seleccionadas por su autora. Su cartografía es un camino con muchos meandros y sinuosidades que le abre múltiples recorridos, todos ellos muy pasionales y vivenciales. Un mapa muy visual, de una maestra apasionada por la palabra pero que "educa la mirada y educa con la mirada". Miradas hacia dentro y hacia fuera, una cartografía visual, pero con algunas pinceladas (¿inevitables? ¿imprescindibles?) de palabras etiquetadas.

El espacio central de su cartografía lo ocupa la letra y la palabra (representada con imágenes). Las escrituras y las lecturas en el centro (lo leído y lo escrito por ella y por otros). Un homenaje a "la abuela Mónica", la persona que le infundió su amor por los libros, por la lectura y por la libertad. Porque para Mónica la lectura y la escritura son ventanas abiertas a la libertad de expresión y de pensamiento.... La abuela Mónica, toda una institución... Y la Universidad (en mayúsculas), la otra institución que le marcó profundamente. La universidad, un espacio de experiencias, de escucha, de diálogo, de búsqueda de libertad, de reflexión y de pensamiento... atravesado por la pasión y la ilusión.

La cartografía y la historia de Mónica es sentir, es conmoción, es recuerdo y es reconocimiento a personas y a instituciones, es luz y vida que empieza y acaba en un espacio.... en un aula. 


\subsection{El sustento de aprender}

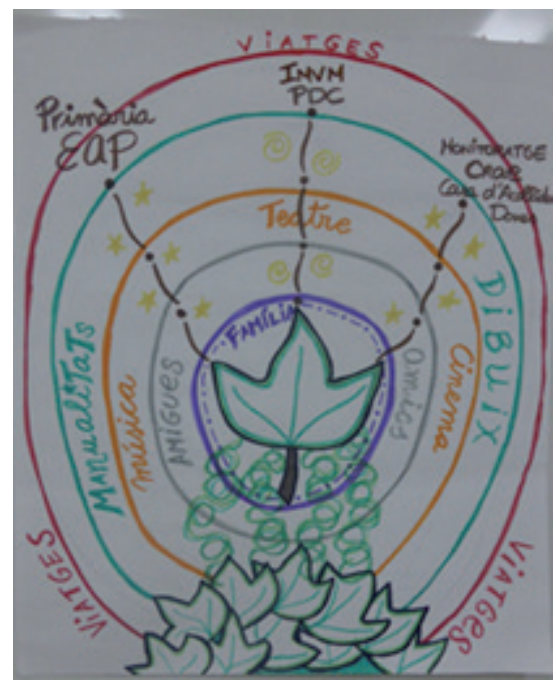

Imagen 2. Cartografía de Sonia. Fotografía independiente.

Fuente: autoría propia.

Sonia estudió pedagogía y en el instituto tiene responsabilidades en la orientación académica, la mediación y el proyecto de diversificación curricular. Fuera del centro tiene distintos intereses: manualidades, montaña, dibujo. Manifiesta "aprender de todo lo que me rodea y me atrae". Sus escenarios actuales de aprendizaje los sitúa en el instituto.

Quizás, por su interés en la educación ambiental utiliza como metáfora un árbol del que nace una hoja que vincula con sus itinerarios profesionales. En torno a esa hoja sitúa todo aquello que dice haberla constituido como persona y como profesional. Representa en su cartografía de aprendizaje 5 círculos concéntricos de distintos colores. El más cercano al núcleo representa la familia, en el corazón de la hoja, enmarcada por un doble círculo, uno de línea continua y otro discontinua (¿la posibilidad/imposibilidad de traspasar los límites de lo familiar?). El segundo lo constituyen los amigos. El tercero sus intereses culturales. El cuarto sus aficiones. En el quinto sitúa los ámbitos en los que ha desarrollado su vida profesional. Fuera del último círculo destaca los viajes, como una actividad envolvente, como un horizonte que aún vinculado a los círculos de su aprendizaje personal y profesional, le permite ir más allá.

En la cartografía aparecen estrellas y espirales que nos sugieren ex- 
pansión y recogimiento a la vez. La opción de vincular una hoja a otras muchas nos hace pensar en la multiplicidad de opciones de representación y de experiencias sin determinar.

Sonia se siente satisfecha de lo que le ha permitido pensar y expresar la cartografía, representa sus lugares y tránsitos de aprendizaje, algo que como investigadoras nos remite a una idea del aprendizaje como el nutriente que posibilita el crecimiento personal y profesional. Un nutriente que encuentra su principal fuente de energía en el contexto familiar. Un nutriente que se refuerza con los amigos, (la auténtica red social, Boltanskiy y Chiapello, 2002), con la experiencia y con el capital cultural (Bourdieu 1997), en este caso relacionado con los entornos culturales y la posibilidad de desarrollar los propios intereses. También nos remite a la imposibilidad de separar el aprendizaje personal y social del profesional.

\subsection{La fuerza de la educación}

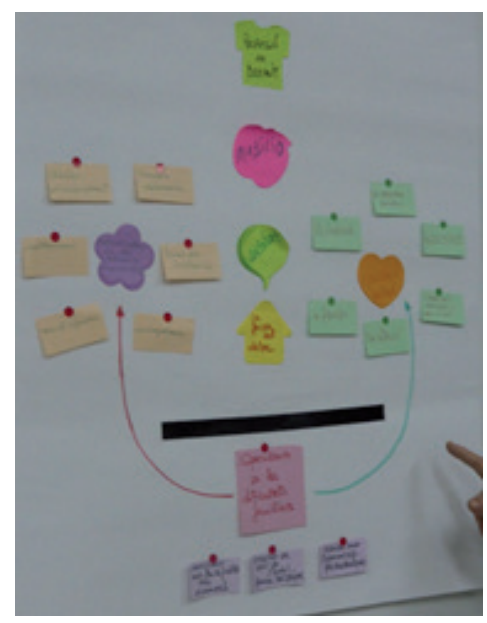

Imagen 3. Cartografía de Alba. Fotografía independiente.

Fuente: autoría propia.

Es el segundo año que Alba trabaja como profesora. Hasta entonces había ejercido como enfermera. Las licenciaturas de Filología Hispánica y Catalana le permiten impartir Literatura y Lengua Catalana en el instituto. Sus experiencias clave de aprendizaje han sido el interés y el gusto por el conocimiento, "ya que he tenido grandes dificultades para conseguirlo".

En la base de la cartografía de Alba vemos una línea negra gruesa que nos sugiere un corte, una separación intencionada y nuclear. Algo que 
nos enfrenta a una "cara seria", a una línea negra de "labios cerrados" de enfado y tristeza. Una línea que marca una fuerte separación entre el "sur", "la supervivencia a las relaciones familiares" y la proyección hacia el norte, a su "ambición". A su deseo temprano de "ser docente". Pero esta "cara seria" es el fermento de su fuerza, de su resiliencia, de su capacidad para enfrentarse a situaciones adversas. Una fuerza que la impulsa a salir de un contexto que frena su crecimiento personal, a realizar aprendizajes no académicos y a identificarse con las dificultades de su alumnado. Porque la línea de labios dura se abre en una sonrisa que impulsa un deseo y una ambición inducidos por el dolor y la curiosidad. A la derecha de la sonrisa, al este, al levante, las emociones: la satisfacción y la felicidad que le proporciona el aprendizaje "informal". A la izquierda, al oeste, a poniente, parece hacerla sonreír la propia discontinuidad de sus escenarios de aprendizaje académico: los estudios que le han posibilitado ejercer la profesión deseada.

En conjunto, nos lleva a pensar que los caminos del aprendizaje de Alba están pavimentados de intensas emociones, sobre todo de dolor. De curiosidad, de afán de supervivencia, de deseo de superación. También de la satisfacción y la felicidad que le produce el propio aprendizaje, a través de la reflexión, la filosofía, las relaciones sociales, las lecturas, el cine, la observación de lo que le rodea. Mientras la discontinuidad señalada entre los escenarios e historias de aprendizaje formal, la lleva a realizar distintos estudios académicos, que le permiten alcanzar su meta: ser docente.

\subsection{Ser en constante cambio, movimiento y aprendizaje}

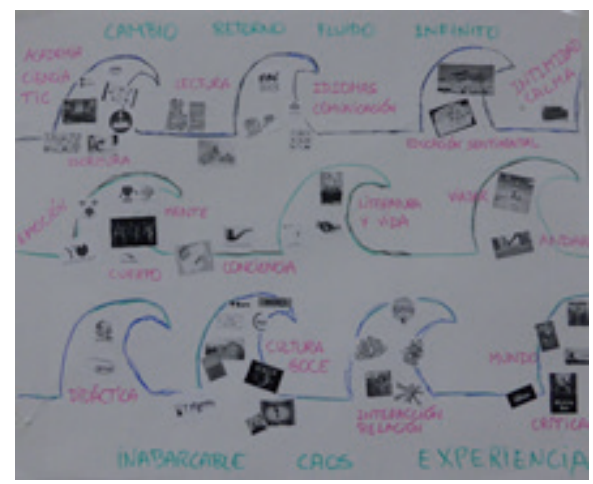

Imagen 4. Cartografía de Montserrat. Fotografía independiente.

Fuente: autoría propia. 
Geografías e historias de aprendizaje de docentes de secundaria. Intersecciones, tránsitos y zonas de no saber

Alejandra Bosco, Cristina Alonso Cano y Raquel Miño Puigcercós

Montserrat es profesora de Lengua Española y describe el aprendizaje como un torbellino que constantemente se expande y se relaciona. En su cartografía, utiliza la metáfora del mar para representar visualmente la asimetría, el descoloque, la fluidez, la infinitud, el retorno y el caos que considera que caracterizan el aprendizaje. Esta metáfora le permite hacer referencia al carácter infinito e inabarcable del conocimiento. El intercalado de dibujos de olas y de mar en calma representan la necesidad de momentos de acción y de reflexión en los procesos de aprendizaje.

El mar de aprendizaje de Montserrat consta de diez olas y diez aguas en calma donde coloca los siguientes "mundos": el académico; la escritura; la lectura; la comunicación y los idiomas; la educación emocional; la intimidad; las emociones; el cuerpo; la mente; la consciencia; la literatura y la vida; los viajes; andar; la didáctica; la cultura del instituto; las relaciones personales; las series de televisión; el mundo y la crítica. Todos estos contextos o "mundos de aprendizaje" van con ella a clase. Por ejemplo, a partir de su propio trabajo emocional, se dio cuenta de que aprender no tiene que ver sólo con procesos mentales, sino también con el cuerpo.

Otra continuidad entre los mundos de aprendizaje de Montserrat se produce a partir de su experiencia profesional en una sección de música clásica de una emisora de radio. Esto le llevó a reivindicar que para disfrutar del arte no es necesario ser un experto y a intentar que sus estudiantes rompan con algunos prejuicios elitistas y disfrutar de ámbitos artísticos como la ópera, el museo o el teatro.

La cartografía de Montserrat es un gran rizoma de eventos de aprendizaje, como si de una planta enredadera se tratara. Sus experiencias se van imbricando y su historia de aprendizaje está conformada por momentos, lugares y personas que no pueden desvincularse. Del mismo modo, la identidad docente de Montserrat no puede desligarse de quién es como aprendiz, como estudiante o como amante de la literatura. Cada uno de sus mundos de aprendizaje confluye y la lleva a ser en constante cambio. 


\subsection{El dinamismo de aprendizaje en la metáfora del río}

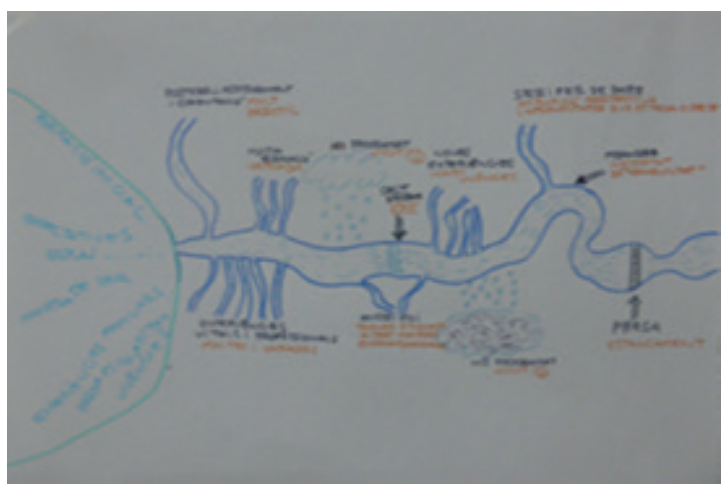

Imagen 5. Cartografía de Manel. Fotografía independiente.

Fuente: autoría propia.

Manel es profesor desde hace 12 años y es su primer año en este instituto. Forma parte del Departamento de Orientación e imparte Lengua Catalana. La metáfora que utiliza es el río, y remite al dinamismo del aprendizaje, dado que un río nunca descansa, siempre corre. Aunque haya momentos, lugares, accidentes que cambien las características de su curso. El curso del río (del aprendizaje) depende de lo que hacemos o no en los diferentes ámbitos de nuestra vida, y de factores externos que no siempre controlamos. Lo ámbitos que destaca Manel son el familiar, privado, y el profesional y de formación. No prioriza un ámbito sobre otro, pero sí distingue experiencias que le llevan a aprender, a veces, al unísono, y otras, cobrando protagonismo un ámbito sobre otro. Todo conecta con la idea de que el aprendizaje es continuo.

Se pueden representar los diferentes accidentes del río como escenarios de aprendizaje. Su nacimiento, representa para Manel, el aporte de sus primeras experiencias vitales, la escuela, lo vivido en el tiempo libre, y también las académicas. No obstante, lo que marca el momento de aprendizaje profesional real, el nacimiento del río, es el comienzo del ejercicio de la profesión, en paralelo al desarrollo de una formación continua polivalente. Este aspecto, la variedad de estudios, actividades o experiencias, conecta, por una parte, con la idea de la necesidad de hacer para aprender, y por otra, con la de realizar actividades muy variadas. También señala experiencias disruptivas que promueven el aprendizaje, unas por interesantes, otras por rutinarias. 
También señala el salto como otra metáfora dentro de la metáfora del río, momento de gran cambio que impulsa hacia el aprendizaje. Ejemplos serían el momento de paso de la escuela concertada a la pública, o la vivencia de ser padre.

Su cartografía también contempla situaciones inesperadas y no buscadas como fuentes de aprendizaje, y también las situaciones no gratificantes como fuente de aprendizaje. Por último, la presa en el río, un momento de estancamiento en el que parece que no avanzamos, también puede promover aprendizaje, ni siquiera en la aparente calma dejamos de aprender.

\subsection{Aprender mediante la conexión y la expansión de experiencias}



Imagen 6. Cartografía de Sara. Fotografía independiente. Fuente: autoría propia.

Desde hace dos años, Sara trabaja como orientadora y profesora de Lengua Catalana y de Cultura y Valores en el instituto. En su cartografía de aprendizaje, utiliza la metáfora de las raíces de un árbol para destacar los momentos más significativos de su historia de aprendizaje. Con esta metáfora, Sara plasma el carácter conectado y relacional de las experiencias y de las relaciones sociales que la llevan a aprender y a configurar su identidad docente. Por eso en las raíces del árbol podemos leer las palabras "familia"; "amistad"; "voluntariado"; "formación"; "experiencia laboral" y "vida". A medida que dibujaba las raíces de su árbol, mencionaba emociones asociadas de cada etapa de 
su vida, como el bienestar, la seguridad, la satisfacción, la ilusión, el caos y la libertad.

La mayoría de las raíces de la cartografía de Sara no están cerradas, sino que conectan entre sí y llegan a un punto final, en la parte inferior. Allí escribe la palabra identidad usando todos los colores que ha utilizado para las raíces. Esto indica que ha construido su identidad a partir de todas las experiencias vividas en las distintas etapas de su vida. Otro elemento de la cartografía que hace referencia a la retroalimentación son dos flechas de color azul y rojo que indican movimiento ascendente y descendente. Estas representan la savia bruta y la savia elaborada del árbol, sin las cuales no podría vivir. Esta metáfora está en consonancia con la noción de identidad de aprendiz de Arnseth y Silseth (2013), quienes consideran que la identidad no solamente se construye mediante la apropiación de "yos", sino que a su vez estos "yos" son evaluados y construidos constantemente por otros.

La cartografía plasma los movimientos de expansión y conexión constante que implica aprender. Del mismo modo que las raíces de un árbol se van expandiendo y conectando, Sara aprende, construye su identidad y expande su conocimiento. Esto nos hace pensar en el aprender como estado de continua expansión, así como en la dificultad de capturar en una cartografía todas las dimensiones del carácter dinámico y fluido del aprendizaje.

\subsection{Implicación, interacción y reflexión}

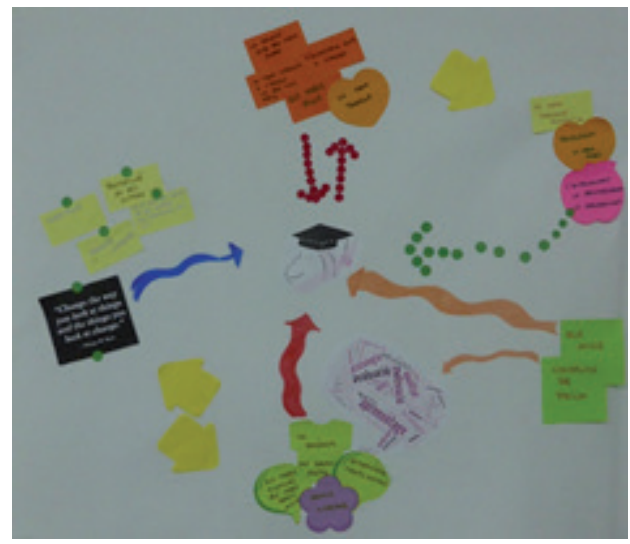

Imagen 7. Cartografía de Teresa. Fotografía independiente.

Fuente: autoría propia. 
Geografías e historias de aprendizaje de docentes de secundaria. Intersecciones, tránsitos y zonas de no saber

Alejandra Bosco, Cristina Alonso Cano y Raquel Miño Puigcercós

Teresa ejerce la docencia desde hace ocho años, es Psicóloga y Psicopedagoga, e imparte Castellano y Cultura y Valores. Se representa a sí misma como el personaje de las tiras de Frato indicando una persona curiosa, activa, reflexiva.

Se sitúa en el centro, lo que conecta con la idea de cómo cualquier aprendizaje debería partir del sujeto: de sus necesidades, conocimientos... Asimismo, este centro recibe influencias de diferentes entornos que aparecen alrededor, cuya relación está marcada con flechas de diferentes tipos. Los entornos están representados con diferentes colores y formas, y su relación sugiere que no son fijos.

El entorno familiar, es el escenario principal de aprendizajes a través de los hijos, la pareja. Sus colores vivos y formas curvas indican su intensidad afectiva y su importancia. La flecha que une a Teresa con este entorno es de doble sentido, por tanto, indica influencias mutuas; conformada por puntos, por tanto, cambiante. Este entorno también conecta con el de formación académica, a través de una flecha corta pero gruesa, es decir, esta formación descansa sobre su bagaje familiar. La flecha que va hacia Teresa desde este entorno es verde, larga y de puntos, indica la tranquilidad que estos conocimientos pueden ofrecerle en su trabajo; los puntos, su dinamismo, todo lo que pueden ofrecerle aplicados en contextos diferentes. Los entornos sociales de amigos y colegas, están unidos a Teresa por dos flechas sólidas algo curvilíneas, naranjas, la de los amigos mucho más gruesa y larga que la otra. Se ven como apoyos importantes, con flechas y curvas que sugieren circunstancias de interacción diversas. La flecha que sale de los colegas conecta con un pequeño mapa conceptual e implica ampliar conocimientos. El entorno de la práctica profesional, representado por post-its de diferentes formas, conecta con Teresa a través de una gruesa y sólida flecha roja. Indica la importancia de la reflexión sobre la práctica y cómo de esa reflexión surge el aprendizaje. Este entorno también está conectado por flechas (dos muy gruesas de ida y vuelta) con el del trabajo personal, vinculado a Teresa con una flecha sólida azul, que sugiere estabilidad. 


\subsection{Lo aprendido y lo que queda por aprender}

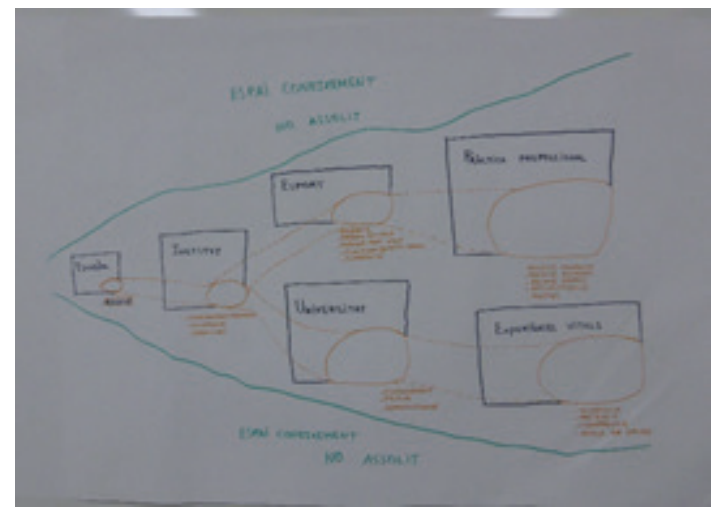

Imagen 8. Cartografía de Lluís. Fotografía independiente.

Fuente: autoría propia.

A Lluís la investigación que nos ocupa le interesa porque si estamos enseñando, hemos de saber cómo hemos aprendido nosotros, y hemos de tener claro "qué es eso de aprender". Al inicio de su carrera entendía la formación reglada como "la formación", en un sentido estricto y en mayúsculas. Actualmente considera que todo lo que viene de fuera es aprender y te puede ayudar a desarrollar tu práctica docente.

Al mirar la cartografía de Lluís vemos una creación "con geometría (¿euclidiana?)", muy "ordenada", muy "arquitectónica" (Lluís es profesor de matemáticas). Tiene un dentro y un fuera, una linealidad geográfica, temporal y cromática muy marcada. En color gris, los escenarios, en color naranja, los aprendizajes que tienen lugar y recorren esos escenarios. Los tamaños de esos escenarios parece que juegan un papel importante en relación a los aprendizajes que tuvieron (y tienen) lugar en ellos. La forma de representar las conexiones y los tránsitos de Lluís, nos evoca una pista de atletismo (Lluís nos había hablado del deporte como detonante de aprendizajes).

Los aprendizajes representados en su cartografía transitan por escenarios formales e institucionales de conocimiento: la escuela, la universidad. Pero también pasan por experiencias (profesionales), actividades (deportivas) y trayectorias (vitales).

Nos Ilama mucho la atención la clara diferenciación que Lluís establece entre dos espacios: (1) el conocimiento "conseguido" (adquirido); 
Geografías e historias de aprendizaje de docentes de secundaria. Intersecciones, tránsitos y zonas de no saber

Alejandra Bosco, Cristina Alonso Cano y Raquel Miño Puigcercós

y (2) el conocimiento "no conseguido" (no adquirido) ... El presente y el futuro, lo que tengo y lo que me falta, lo aprendido y lo que le queda por aprender... Un reconocimiento del pasado y un posicionamiento optimista en el futuro... lo que me depara, lo que me espera, lo que aprenderé, "lo que necesito para seguir avanzando". Un espacio de conocimiento "no conseguido", un lugar desconocido, por descubrir, en términos cartográficos. Un espacio como la pista de atletismo por la que transitan Lluís y sus aprendizajes, con una salida pero sin una meta, con un comienzo, pero sin un final. Un lugar con una circularidad que le permite perseguir y moverse en la búsqueda constante del reto y la superación, del conocimiento no alcanzado, pero contemplado, buscado y deseado.

\section{Resultados y Discusión}

La introducción de una dimensión espacial (territorial, geográfica) y visual en las historias de aprendizaje del profesorado, nos ha abierto un panorama de gran complejidad. En algunas de las cartografías presentadas predomina la dimensión geográfica, sus autores utilizaron metáforas espaciales para representar el aprendizaje (un camino, un mar o un río). Esto nos da la oportunidad de aproximarnos a sus trayectorias de aprendizaje tomando como referencia los conceptos "espacio liso" y "espacio estriado" de Deleuze y Guattari (1980/2004). Según estos autores, el espacio es liso o estriado en función de cómo se subordinan los trayectos a los puntos o los puntos a los trayectos. Por ejemplo, una ciudad es un espacio estriado, en tanto que los transeúntes siguen unos trayectos concretos para moverse de un punto a otro, mientras que un océano es un espacio liso, puesto que al navegar el camino no está acotado como sucede en una ciudad.

Un ejemplo del uso de estos conceptos en el análisis de las cartografías sería la geografía de aprendizaje de Montserrat. Ella hace referencia al mar como espacio liso, infinito, que posibilita una navegación fluida, caótica e inesperada. La cartografía de Manel también hace referencia a una metáfora espacial relacionada con el agua, un río, un espacio más estriado, que tiene un inicio y un final, un trayecto (más o menos) delimitado entre dos puntos. Pero en su relato tiene mucha presencia el azar, considera que el río siempre está en movimiento y que existen 
momentos, lugares y accidentes que hacen que vaya más rápido, menos rápido, con más caudal o menos, desbordándose, inundando o provocando sequía.

Esta aproximación a las cartografías nos lleva a pensar en que habitualmente concebimos la formación docente desde una noción de aprendizaje estriado, con un principio y un final: si los estudiantes realizan una serie de lecturas, ejercicios y actividades, aprenderán. Sin embargo, el profesorado, mayoritariamente, cartografía sus trayectos de aprendizaje en espacios lisos, no subordinados a la unión de dos puntos previamente delimitados. Los puntos de sus cartografías se aproximan, se encuentran a medida que viven experiencias y las relacionan entre sí.

Unas experiencias que no pueden contemplarse de forma aislada, en un territorio, ámbito o contexto determinado, desconsiderando el resto de territorios. Los docentes asignan un territorio o espacio en sus cartografías, a los diferentes ámbitos en los que aprenden (familia, amigos, ocio, cultura, escuela...), al tiempo que explicitan múltiples intersecciones y tránsitos entre unos y otros. En ningún caso, los territorios se contemplan como compartimentos estancos. No parece haber "un dentro" y "un fuera" del centro. Las experiencias de aprendizaje fluyen de unos espacios (ámbitos) a otros (Banks et al., 2007). Tampoco parece atribuirse el aprendizaje a una relación causal o jerárquica. Como si de un rizoma se tratase, las relaciones entre diferentes nodos (experiencias) no están ni pueden determinarse... suceden (Cumming, 2015).

Si tuviéramos que encontrar una lógica o entramado a la relación entre estos espacios de aprendizaje, más allá de ser espacios lisos o estriados, quizás la más plausible es la biografía. El aprendizaje se revela completamente vinculado a las experiencias vitales que trascienden los ámbitos, y es ese carácter vital-biográfico el que los mantiene vinculados.

Por último, cabe destacar otras dimensiones del aprendizaje que emergen de las cartografías y que ayudan a entender cómo aprenden estos docentes tal y como indican otros estudios (Arnseth y Silseth, 2013; Darling-Hammond y Richardson, 2009; Escudero, Cutanda y Trillo, 2017): (1) la importancia del aprendizaje experiencial, aprender en y de la práctica, aprender haciendo; (2) el papel de la reflexión en la acción o práctica reflexiva; (3) la importancia de partir de intereses genuinos que les mueven, emocionan y los convierten en protagonistas; (4) el trabajo con el otro y los otros; y (5) la conciencia del no saber y de ser aprendiz de por vida. 
Geografías e historias de aprendizaje de docentes de secundaria. Intersecciones, tránsitos y zonas de no saber

Alejandra Bosco, Cristina Alonso Cano y Raquel Miño Puigcercós

\section{Conclusiones}

El proceso de análisis de la experiencia de investigación como un todo, nos posibilita reconfirmar el enorme potencial de las cartografías, no sólo como un método visual y creativo de elicitación, sino como un 'espacio' en el que cuerpos, cosas, textos, situaciones, ideas y maneras de hacer se entremezclan. Un espacio en el que los participantes de la investigación son quienes deciden qué contar y cómo hacerlo y los investigadores les acompañan (y respetan) en la creación de unas trayectorias de aprendizaje que adoptan una multiplicidad de formas de expresión.

Nuestra investigación evidencia que el aprendizaje no es un resultado. Es una actividad puesta en marcha dentro de una ontología procesual, relacional y performativa del devenir (Barad, 2007). Un proceso que, como argumenta Phillips (2014), "involves real people who live in real, complex social contexts from which they cannot be abstracted in any meaningful way" (p. 11).

\section{Referencias}

Arnseth, H.C., y Silseth, K. (2013). Tracing Learning Identity Across Sites: Tensions, Connections and Transformations in and Between Everyday and Institutional Practices. En O. Erstad y J. Sefton-Green (ed.) Identity, community, and learning lives in the digital age. (pp. 23-38). Nueva York: Cambridge.

Atkinson, D. (2011). Art, Equality and Learning: Pedagogies Against the State. Rotterdam: Sense Publishers.

Ball, S. J., y Goodson, I. F. (1985). Teachers' lives and careers. Philadelphia: Falmer Press. Banks, J. A., Au, K. H., Ball, A. F., Bell, P., Gordon, E. W., Gutiérrez, K., Heath, S. B., Lee, C. D., Lee, Y., Mahiri, J., Nasir, N. S., Valdes, G. I., y Zhou, M. (2007). Learning in and out of school in diverse environments. Life-long, life-wide, life-deep. Seattle. Recuperado de: http://life-slc.org/docs/Banks_etal-LIFE-Diversity-Report.pdf [23.03.2017]

Barad, K. (2007). Meeting the Universe Halfway: Quantum Physics and the Entanglement of Matter and Meaning. Durham: Duke University Press.

Boltanski, L., y Chiapello, È. (2002). El nuevo espíritu del capitalismo. Madrid: Akal.

Bourdieu, P. (1997). Capital Cultural, Escuela y Espacio Social. México, D.F.: Siglo XXI.

Braidotti, R. (2006). Transpositions. On Nomadic Ethics. Cambridge: Cambridge Polity Press.

Braidotti, R. (2014). Writing as a nomadic subject. Comparative Critical Studies, 11(2-3), 163-184.

Bruner, L. (1977). The Relevance of Education. New York: Norton.

Calderhead, J. (ed.) (1987). Exploring Teacher Thinking. London: Cassell. 
Geografías e historias de aprendizaje de docentes de secundaria. Intersecciones, tránsitos y zonas de no saber Alejandra Bosco, Cristina Alonso Cano y Raquel Miño Puigcercós

Carr, M., y Lee, W. (2012). Learning Stories: Constructing Learner Identities in Early Education. London: SAGE.

Darling-Hammond, L., y Richardson, N. (2009). Research Review / Teacher Learning: What Matters?. Educational Leadership, 66(5), 46-53.

Cumming, T. (2015). Challenges of 'thinking differently' with rhizoanalytic

approaches: a reflexive account. International Journal of Research \& Method in Education, 38(2), 137-148.

Deleuze, G., y Guattari, F. (2004). A thousand plateaus. London: Continuum.

Erstad, O. (2015). Learning Lives Across Educational Boundaries: Continuity and Discontinuity in Learning Trajectories. IJREE, 3(2), 9-22.

Escudero, J. M., Cutanda. M. S., y Trillo, F. (2017). Aprendizaje docente y desarrollo profesional del profesorado. Profesorado. Revista de Currículum y Formación del Profesorado, 21(3), 83-102.

Fendler, R. (2013). Becoming-Learner: Coordinates for Mapping the Space and Subject of Nomadic Pedagogy. Qualitative Inquiry, 19(10), 786-793.

Fendler, R. (2015). Navigating the eventful space of learning: Mobilities, nomadism and other tactical maneuvers (Tesis doctoral inédita). University of Barcelona, Barcelona.

Fullan, M. (2016). The new meaning of educational change. New York: Teachers College Press.

Goodson, I. F., y Hargreaves, A. (eds.) (1996). Teachers' professional lives. London: The Falmer Press.

Goodson, I. F., y Sikes, P. (2001). Life history research in educational settings. Buckingham: Open University Press.

Guattari, F. (2012). Schizoanalytic Cartographies. Bloomsbury: London.

Hargreaves, A. (1994). Changing teachers, changing times: teachers' work and culture in the postmodern age. New York: Teachers College Press.

Jackson, A.Y., y Mazzei, L. (2012). Thinking with theory in qualitative research: Viewing data across multiple perspectives. New York: Routledge.

James, M., y McCormicki, R. (2009). Teachers learning how to learn. Teaching and Teacher Education, 25(7), 973-982.

Korthagen, F. (2017). Inconvenient truths about teacher learning: towards professional development 3.0. Teachers and Teaching: theory and practice, 23(4), 387-405.

Lury, C., y Wakeford. N. (Ed.) (2012). Inventive Methods: The Happening of the Social (Culture, Economy, and the Social). New York: Routledge.

McNamara, D. (2006). Research on Teachers' Thinking: its contribution to educating student teachers to think critically. Journal of Education for Teaching, 16(2), 147 160.

Miño Puigcercós, R. (2018). Young people's trajectories in the digital age. Digital Education Review, 33, 39-54.

Mishra, P., y Koehler, M. J. (2006). Technological pedagogical content knowledge: a framework for integrating technology in teacher knowledge. Teachers College Record, 108(6), 101-154.

Phillips, D. C. (2014). Research in the Hard Sciences, and in Very Hard "Softer" Domains. Educational Researcher, 43(1), 9-11. 
Geografías e historias de aprendizaje de docentes de secundaria. Intersecciones, tránsitos y zonas de no saber

Alejandra Bosco, Cristina Alonso Cano y Raquel Miño Puigcercós

Putnam, R. T., y Borko, H. (2000). What do new views of knowledge and thinking have to say about research on teacher learning? Educational Researcher, 29(1), 4-15.

Rodrigo, M. J., Rodríguez, A., y Marrero, J. (1993). Las teorías implícitas. Una aproximación al conocimiento cotidiano. Madrid: Visor.

Ruitenberg, C. (2007). Here be dragons: Exploring Cartography in Educational Theory and Research. Complicity: An International Journal of Complexity and Education, 4, 7-24.

Sancho, J. (Coord.), (2011). Con voz propia. Los cambios sociales y profesionales desde la experiencia de los docentes. Barcelona: Octaedro.

Sancho, J. (Coord.) (2013). Trayectorias docentes e investigadoras en la universidad. 24 historias de vida profesional. Barcelona: Dipòsit Digital de la Universitat de Barcelona. Recuperado de: http://hdl.handle.net/2445/44965 [13.03.2018]

Sancho, J. y Hernández, F. (2014). Maestros al vaivén. Aprender a ser docente en el mundo actual. Barcelona: Octaedro.

Sarason, S. (1990). The predictable failure of educational reform: can we change course before it's too late? San Francisco: Jossey-Bass.

Sefton-Green, J. (2017). Representing learning lives: what does it mean to map learning journeys? International Journal of Educational Research, 84, 111-118.

Shulman, L. S. (1987). Knowledge and teaching: Fundaments of the new reform. Harvard Educational Review, 57(1), 1-22.

Shulman, L. S. y Shulman, J. H. (2004). How and what teachers learn: a shifting perspective. Journal of Curriculum Studies, 36(2), 257-271.

Stenhouse, L. (1975). An introduction to curriculum research and development. London: Heinemann.

Stoll, L., y Fink, F. (1996). Changing Our Schools: Linking School Effectiveness and School Improvement. Buckingham: Open University Press.

Tenti, E. (2010). Configuraciones sociales y culturales de estudiantes y docentes de los ISFD: algunas claves interpretativas. En E. Tenti (coord.), Estudiantes y profesores de la formación docente: opiniones, valoraciones y expectativas (pp. 11-34). Buenos Aires: Ministerio de Educación de la Nación.

Ulmer, J. B., y Koro-Ljungberg, M. (2015). Writing Visually Through (Methodological) Events and Cartography. Qualitative Inquiry, 21(2), 138-152.

Vélaz de Medrano, C., y Vaillant, D. (Coord.) (2009). Aprendizaje y desarrollo profesional docente. Madrid: OEIA/Fundación Santillana.

Warf, B., y Arias, S. (eds.) (2008). The Spatial Turn: Interdisciplinarity Perspectives. New York: Routledge.

\section{Financiación}

El proyecto [nombre el proyecto] está siendo parcialmente financiado por el Ministerio de Economía, Empresa y Competitividad. [Número del proyecto y número del proyecto] 


\section{Agradecimientos}

Nombre del proyecto: Cómo aprenden los docentes: Implicaciones educativas y retos para afrontar el cambio social - APREN-DO. Número del proyecto: EDU2015-70912-C2-1-R.

Grupo de investigación [ESBRINA. Subjetividades, visualidades y entornos educativos contemporáneos. Número referencia grupo: 2017-SGR 1248. Página web: http://esbrina.eu/es/inicio/].

Red de excelencia [REUNI+D. Número de referencia de la red: EDU201568718-REDT. Página web: http://reunid.eu/]. 
